\title{
THE TREATMENT AND ORIGIN OF HAMMER-TOE.
}

\author{
BY ROBERT LAFAYETTE SWAN, F.R.C.S.;
}

Surgeon Dublin Orthopæedic Hospital, and Steevens' Hospital.

I ASK your attention to this subject for a short time for the following reasons:-

That it is an affection which in exaggerated cases produces the utmost misery and suffering. That the instances which exist are very numerous. That the literature of this subject is in books of standard reference in surgery singularly scanty, and the directions given for its treatment I believe inefficient: and lastly, that while in certain papers which within the last few years have dealt with the subject, the conditions which co-exist with the deformity are described, no attempt, so far as I can discover, has been made to arrive at an explanation of the true origin of this distortion.

For several years past my attention has been directed towards these points, and I venture to submit the deductions, both practical as to its treatment, and theoretical as to its origin, to the consideration of the academy.

I cannot better illustrate the distress occasioned by this distortion than by reading the following extract from the letter of a gentleman:-_" My wife, aged 24, has had as long as she can remember a bent.condition of the second toe on each foot, and latterly she has endured the greatest misery from it. She is fond of riding, but camnot wear a boot. The top of the toe is flattened and very painful, and seems, no matter what kind of boot she wears, to always press violently against the sole. The nail is thickened and loosened, and a slight discharge comes from under it. The upper part of the toe, 
if she tries to wear a decent boot, becomes easily inflamed. Though actively inclined, she can neither walk, play tennis, ride, nor take any active exercise, and it renders her life quite wretched." These casts were taken from the feet referred to before treatment.

On reference to standard surgical works, it will be found that no notice is taken of this affection by Gant, Fergusson, or Agnew. Gross classes it with hallux flexus, and considers it easily cured by section of the flexor tendons. Now, it is completely distinct from hallux flexus, which occurs only in males, and is an acquired affection, whereas hammer-toe is common to males and females, always I believe congenital and often hereditary. In the article written by Dr. Little for Holmes' system of surgery, he also advocates section of the flexor tendons. Mr. Erichsen describes it in the following words:- "In this complaint the proximal phalanx is on its normal level, or slightly drawn up. The two distal are bent down at an acute angle, the apex of which is formed by the articulation of the first with the second. This contraction more commonly affects the second toe, is often symmetrical in both feet, and is frequently a source of great inconvenience and even permanent lameness. It appears to be due to contraction of the digital prolongation of the plantar fascia, and is best remedied by dividing this subcutaneously." In the French medical society, in 1888, M. Terrier read a paper on the treatment of hammer-toe by resection of the first interphalangeal joint. Messrs. Bran and Charles had previously reported similar cases. Mr. Adams recommends the section of the lateral ligaments, the shortening of the inferior fibres of which he considered the cause of the deformity. He probably meant the fibrous bands connecting the sheaths of the tendons with the lateral ridges on the phalanges. Mr. Anderson, in 1889, also gave a very clear description of the conditions that exist, and the means to be adopted for 
vectification. Most men are disposed to be led by generally accepted doctrines, and it is a tendency which has its wholesome deterrent uses. I followed those doctrines for some year's, divided the flexor tendons and the ligamentous structures, with occasionally some little improvement, and perhaps in slight cases with success, but the mortification of failure led me to seek some surer method of dealing with this condition. In $1885 \mathrm{I}$ removed the hear of the first phalanx, after a thorough and repeated examination of the anatomy of the distortion and trials on the dead subjects. The rectification was immediate and complete. I have since operated on a large number of cases in which the distortion was often symmetrical. The results were invariably all that could be desired.

Through the kindness of Professor Frazer I am able to produce this dissection of hammer-toe. 'The first phalanx is in its natural position. The second and third are flexed. The sheath is opened and the tendens are loose, and yet we see the deformity remains unaltered. 'The head of the first phalanx is only partially in the articulation, and is marked by a transverse ridge dividing the articular from the non-articular portion. The non-articular portion shows a deficient incrustation of cartilage, and is covered by the extensor aponeurosis which plays over it. The fibres which attach the anterior part of the first and proximal extremities of the second phalanges to the sheath are shortened, and appear to be at this stage of the dissection the immediate cause of the distortion. But we know that all structures, such as here exist, rapidly adapt themselves to assumed positions of the skeleton. This is well seen in diseases of joints, and in many congenital or acquired deformities. Let us take, for example, the ordinary equino-varus. Here we have ligaments, tendons, fascia, blood-vessels, nerves, and skin, all shortened, and it would be equally logical to state that one of those structures was a 
factor of the condition is another, unless we could clearly demonstrate it to be so. We have in this deformity the ligaments, the sheaths of the tendons, the tendons, the subcutaneous slips of fascia, the skin itself equally shortened; but these are, I believe, the result, not the cause of the condition existing, as the removal of a portion of the skeleton produced ready rectification. I was led to believe that it alone was in fault, and if content with the satisfactory result of the application of such knowledge, all was easy; but here I was confronted by the problem-Why should the second toe be invariably so affected? There are certain facts which point to its elucidation, which I shall briefly relate.

Apart from progression, the functional uses which the toes may serve are varied. The Polynesians, Dyaks, negroes, and certain tribes of Indians, have an extraordinary dexterity in grasping objects with their toes, or between the first and second toe. There are tree dwellers amongst the Indian tribes, residing along the Amazon rivers, engaged in the collection of India-rubber, who have wonderful powers of grasping objects with their toes. It is stated by Hartmann that among many of those people the great toe, even in rest, is separated from the second, and the distinction between the foot of man and that of the anthropoid apes is less marked. There is a tribe in Central Africa, named Makrata, in which this is extremely evident.

Dr. Buckmer (Conférences su' la théorie Darwiniensis) has also given cases of the use of the foot as a prehensile organ in man. The great toe of all anthropoid apes is shorter than the second, and extremely small in some. Through the kindness of my friend, Professor Cumningham, I am able to show this exemplified in the feet of the chimpanzee, the orang outang, and the gibbon. So that really in some of these the action of the foot as a prehensile organ must, in powerful efforts, be more of a grasper by the flexors of the toes than. 
by the opposing power of the great toe to the others or to the sole. Man alone is characterised by the possession of a great toe longer than the second, although this appears to be by no means a constant feature. In Greek sculpture the second toe is represented as longer than the first, as is seen in the statues of the Hercules Farnese and the Apollo Belvidere. This was probably copied by the Egyptians, and originally derived by them from the negro. Here we see evidence of a reversion to a lower type of foot. Professor Flower examined the feet of many hundreds of children who had naked and therefore undeformed feet, and did not find a single instance of the second toe being longer than the first; but if we measure the disarticulated bones of a hammer-toe, we always find it longer than the first. The anatomy of the second toe shows that it is admirably adapted for functional usefulness. It has two dorsal interrossei which, as proved by Duchenne, serve to extend the first phalanx, and help to flex the second and third; but they also must contribute to lateral motion. The extensor aponeurosis is attached to the second and third. The flexor attachments to the second and third phalanges are most powerful. In the case of an accidental mutilation it serves as an admirable substitute for the wonderful versatility of motion afforded the great toe by its seven special muscles. Here is an illustration of the development of the second toe in such a case; but this endowment must mean more than merely to meet the necessities of an accidental mutilation.

In the works of most of the older anatomists we find that the second toe is depicted as longer than the great toe. This is particularly evident in the plates illustrating the works of Haller, which I examined through the kindness of my friend Dr. William Frazer, and which are so generally accurate. It has been asserted by Weissmann that mutilations are not hereditably transmittable. The idea, which is seriously stated 
by many writers, that this distortion is a mutilation-that is, produced by an ill-fitting boot-may be at once discarded. It has no such origin, and is, I believe, always congenital, although the inconvenience of the conformation does not arise till the foot has been used, and it may certainly be aggravated by ill-fitting boots. It is also of ten hereditary, and most frequently is found in the second toe of both feet. This would, if Weissmann be correct, bear out the view that it is not a mutilation. We are not without evidences in the human foot of being, in the process of evolution, closely allied to a lower type. The anthropoid apes have the sole of the foot turned inwards, and rest on the outer side of the footin fact, they have naturally an equino-varus. And here again in such a deformity we see a reversion to a lower type. Such a condition, I am informed by Professor Fraser, is proper to the embryonic foot even to a tolerably advanced period of development. The same distinguished embryologist has informed me that the fibula in the fotus does not descend below the level of the internal malleolus, as he has demonstrated by numerous sections of the fotal tarsus. This is a complete similitude to the fibula of the anthropoid apes, and is an adaptation of structure to function, as the arrangement affords more freedom of motion, but less strength to the ankle-joint, with the result that man, when developed, enjoys greater power for the maintenance of the erect posture, and the exceptional privilege in the animal series for the acquirement of a Pott's fracture. From this combination of facts, very imperfectly expressed, I venture to suggest that the deformity known as "hammer-toe" is a partial reversion to a lower type of foot, and that the osseous elements of the grasping toes are developed out of all proportion to the soft structures. 
Mr. Hamilon considered the Academy was indebted to Mr. Swan for his paper, which was characterised by originality and research, as well as by practical usefulness. 'The surgeon was apt to follow routine, and he had himself on many occasions divided the flexor tendons for this affection. He had no doubt, from what he now saw, such teaching was erroneous. He had himself been struck with the functional usefulness acquired by the toes, as illustrated by the divers in the Bay of Naples.

Mr. T. Myles congratulated the Section on the pleasure and benefit they had derived from listening to Mr. Swan's very exhaustive paper. The speaker, however, disagreed with some of $\mathrm{Mr}$. Swan's statements, and considered that his deductions were hardly warranted in their entirety. For instance, the second toe, normally, was not shorter but always longer than the first. Mr. Myles pointed out that in the condition under discussion the position of flexion of the second toe had the effect of removing the broad anterior extremity of the phalanx from between the first and third, and was, in fact, nothing more than a spontaneous effort to diminish the effects of the crowding together of the toes by tight boots. 'If Mr. Swan's theory were true, it ought to be equally common amongst people who do not wear boots as amongst those who do.

Mr. Wheecer thought that the last speaker argued from the particular to the universal. In any cases he had seen of hammertoe he was led to believe that it was congenital. On two occasions he excised the joint and placed the toe in the straight position.

Mr. Pratr referred to the evolutionary development which occurred in the feet of birds as having some bearing on Mr. Swan's explanation of the origin of this affection. 